\title{
Changes in areal extent, elevation and volume of Athabasca Glacier, Alberta, Canada, as estimated from a series of maps produced between 1919 and 1979
}

\author{
J. R. Reynolds, G. J. Young \\ Cold Regions Research Centre, Wilfrid Laurier University, Waterloo, Ontario N2L 3C5, Canada
}

\begin{abstract}
Changes in planimetric area, elevation and volume were calculated for Athabasca Glacier, Alberta, Canada, below $2400 \mathrm{~m}$ elevation for the period 1919-79 from maps produced using aerial or terrestrial photogrammetry. Map contours were digitized and converted into raster digital elevation models (DEMs). Comparison of the models allowed changes in volume and elevation to be estimated. In the time of record, the glacier lost $2.344 \times 10^{8} \mathrm{~m}^{3}$ of volume and downwasted significantly.

There are several sources of error associated with DEM generation and construction: source maps have spatially variable uncertainty in vertical estimation, associated with the photogrammetric process used; small errors are introduced in the creation of raster DEMs as a result of fitting surfaces to digitized contours; errors of registration, leading to errors in estimation of vertical change over time, can be of significance, especially when comparing maps produced by different photogrammetric techniques.

These errors are quantified and displayed in transect and map form. Especially with maps only 2 years apart in time, errors are often greater than actual changes in surface elevation. The magnitude of the errors involved in the comparison of maps made with a 2 year interval would suggest that 5 or 10 years between successive mappings might have been more scientifically justifiable and more cost effective.
\end{abstract}

\section{INTRODUCTION}

Athabasca Glacier is located at $52^{\circ} 12^{\prime} \mathrm{N}, 117^{\circ} 14^{\prime} \mathrm{W}$, inside Jasper National Park on the Alberta-British Columbia border (see Fig. 1). It flows in a north-northeast direction off the Columbia Ice Field over three icefalls into an alpine valley. Debris covers approximately one-third of the western margin of the ablation area. Athabasca Glacier was mapped many times using different methods between 1919 and 1979. These maps were converted into raster (grid square) digital elevation models (DEMs) and used to calculate the surface and volumetric change of the glacier over that period of time.

The main part of the ablation area lying between the terminus (at $\approx 1950 \mathrm{~m}$ ) and $2400 \mathrm{~m}$ a.s.l. was studied. It is in this zone that the greatest changes have occurred and that the precision of measurement by the methods of mapping used is highest.

Glacier dynamics, the influence of bedrock configuration on glacier motion, and the relative importance of surface melt and emergence velocities are not included within the scope of this paper. It was initially hoped that the results would be of relevance in the study of kinematic waves. However, it was found that the original data are not sufficiently precise to reliably detect surficial changes associated with kinematic waves.

\section{DATA SOURGES}

Using DEMs to calculate and show how the glacier has changed over time requires accurate, quantitative informa- tion portraying the glacier surface at different times. For Athabasca Glacier, this is stored in a series of contour maps. Table 1 summarizes the information concerning the production of the maps used for this study.

\section{Glacier margins}

The studied part of the glacier consists of flowing debriscovered and clear ice, with stagnant debris-covered ice in lateral moraines surrounding the glacier. Changes in stagnant ice were not measured. Therefore, the lateral extents of the flowing ice were estimated for each of the maps used in this study using both the maps themselves and aerial photography from the nearest year. Figure $2 \mathrm{a}, \mathrm{d}$ and e demonstrate that the method of edge estimation used was not very successful since the borders recorded do not display a logical progression of change between years.

\section{Georeferencing}

On each map there are printed points which state explicitly their location in Universal Transverse Mercator coordinates or latitude and longitude. If georeferencing is the same on all maps then they can be compared without difficulty. Unfortunately, the georeferencing of the small-scale maps did not agree with that of the large-scale maps. Due to its superior labelling of georeferencing points and since its referencing is determined in relation to the national georeferencing network, the 1955 map is assumed to be the most positionally accurate.

The small-scale 1919 map required a slight stretch in the north-south direction and a small displacement to bring it 

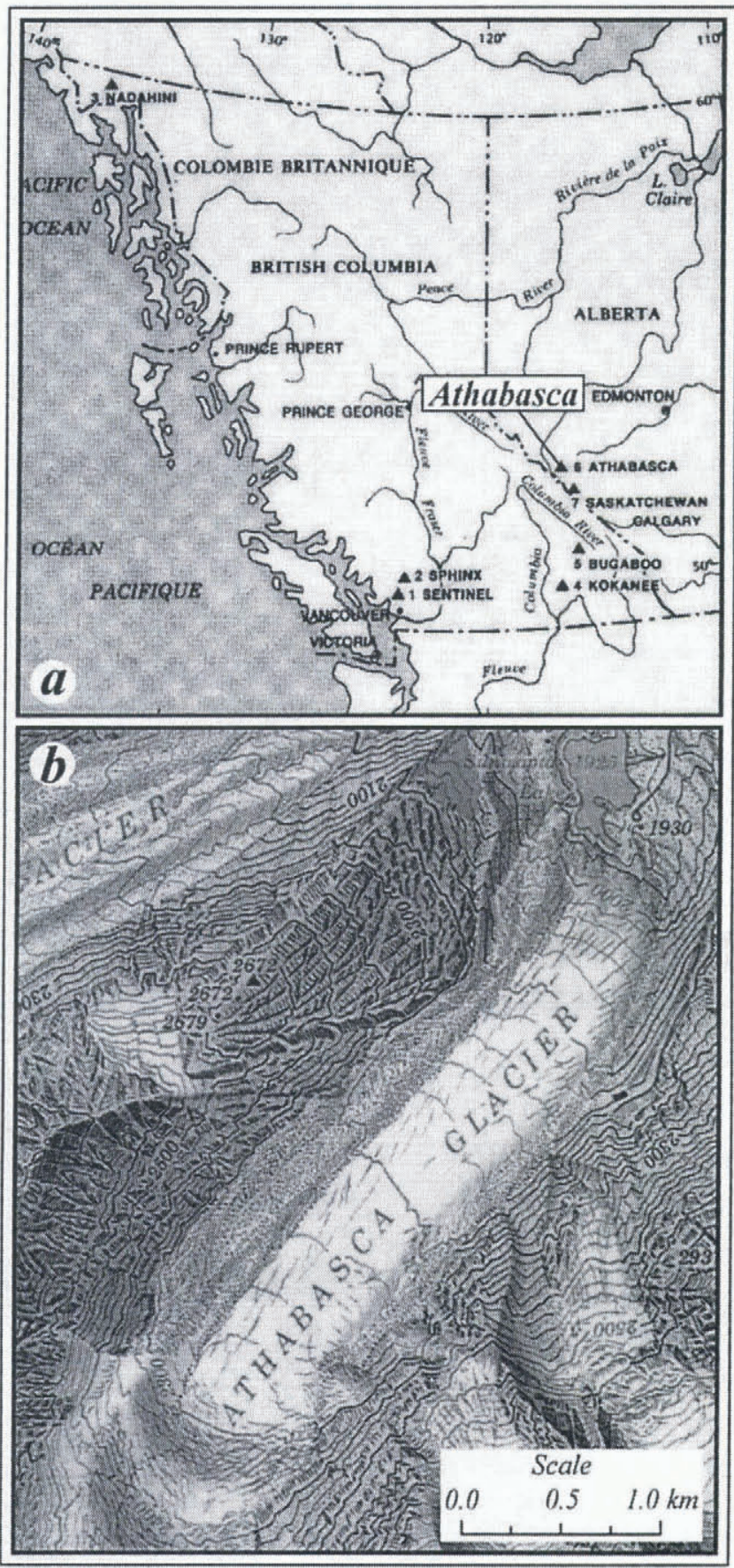

Fig. 1. Athabasca Glacier. (a) Location (from Reid and Charbonneau, 1981). (b) Ablation area (Parks Canada, 1980).

into agreement with the 1955 map. The large-scale maps shared an internal georeferencing but were displaced slightly with respect to the 1955 map. To be brought into agreement with the 1955 map, they were displaced $161.4 \mathrm{~m}$ in the direction $66.7^{\circ}$ east of south. Neither the 1919 map nor the large-scale maps displayed any rotational errors with respect to true north.

\section{GENERATING THE SURFACES}

The contour lines of the source maps were digitized, producing a series of $(x, y, z)$ elevation points from each map. The number of points digitized varied with the scale of the map, having 4000-7000 points for small-scale maps and greater than 11000 points for each of the large-scale maps. For each of the maps, the surface of the glacier and the valley walls surrounding it had the greatest density of digitized points, while the surrounding area had few data points, widely dispersed. The effect of this was that the extra-glacier surface interpolation was less accurate. In a high-relief area, a slight horizontal displacement results in a large vertical non-coincidence.

The package Surfer 5.01 for Windows was used to generate raster surfaces from the $(x, y, z)$ data files. Surfaces were created by overlaying a regular rectangular grid having spacing of $5 \mathrm{~m}$ over the mapped area of the glacier. The elevation at each of the grid nodes was interpolated from surrounding data points using universal Kriging with a linear semi-variogram. This method was relatively fast and produced surfaces that when compared with the original data points had residuals ranging in magnitude from 0.09 to $0.34 \mathrm{~m}$ over $50 \mathrm{~m}$ elevation zones of the glacier.

\section{GHANGE AND GOMPARISON: RESULTS}

The results reported in this paper do not measure mass balance, since information was neither collected on a yearly basis nor acquired at the end of the ablation season. Thus the values of surface and volumetric change derived do not reflect changes between one hydrological year and the next: change is measured between one map and the next.

The results of surface change in terminal position will be considered first, followed by a discussion of volumetric change.

\section{Terminal position}

Figure 2a illustrates a retreat of the central part of the glacier terminus of $\approx 1 \mathrm{~km}$ between 1919 and 1979. The former extent of the glacier and its rates of recession were determined by Luckman (1988) using old photographs, dendrochronology and the dating of recessional moraines.

The positions of the clear-ice terminus were determined solely from the terminus positions marked on the maps used to produce DEMs. The terminus of the debris-covered part was marked on no map. Air photo interpretation was used to estimate the terminus of the flowing debris-covered glacier in each of the years of mapping.

Additionally, terminus positions were not located with sufficient precision on the large-scale maps. Field observations at the time of record (Luckman, 1988) indicated that no readvances occurred, but some of the maps show slight readvances over limited parts of the terminus.

\section{Area}

As the glacier receded from 1919 to 1979, its area below $2400 \mathrm{~m}$ a.s.l. also decreased. One of the most notable trends is its great loss of area below $1950 \mathrm{~m}$. In 1919, more than $100000 \mathrm{~m}^{2}$ of its planar area was below $1950 \mathrm{~m}$ a.s.l. In 1979 , less than $1500 \mathrm{~m}^{2}$ of its area was below that elevation. The elevation zone $1950-2000 \mathrm{~m}$ a.s.l. records a similar but not as precipitous decrease in area.

When $50 \mathrm{~m}$ elevation zones between $2150-2400 \mathrm{~m}$ a.s.l. are considered, measured areas in given zones are fairly constant. The greatest yearly variability of area occurred in the elevation zone $2200-2300 \mathrm{~m}$, the flattest section of the glacier. 
Table 1. Summary of data sources

\begin{tabular}{|c|c|c|c|c|c|}
\hline Date & Producing body & Method of production & Map Scale & Photo Scale & Contour interval \\
\hline 1 and 9 August 1919 & $\begin{array}{l}\text { Alberta-British Columbia } \\
\text { Boundary Commission }\end{array}$ & $\begin{array}{l}\text { Terrestrial non-parallel } \\
\text { photogrammetry }\end{array}$ & $1: 62500$ & & $100 \mathrm{ft}(30.48 \mathrm{~m})$ \\
\hline 28 August 1955 & National Topographic Service & Aerial photogrammetry & $1: 50000$ & $1: 10700$ & $100 \mathrm{ft}(30.48 \mathrm{~m})$ \\
\hline 1 August 1959 & Water Resources & Aerial photogrammetry & $1: 4800$ & $1: 4100$ & $10 \mathrm{ft}(3.048 \mathrm{~m})$ \\
\hline $\begin{array}{l}25 \text { July }-27 \text { August } \\
1965-79 \text { (eight maps) }\end{array}$ & Inland Waters & Terrestrial photogrammetry & $1: 10000$ & - & $\begin{array}{l}\text { 1965, 1967: } 25 \mathrm{ft}(7.62 \mathrm{~m}) \\
1969-79: 5 \mathrm{~m}\end{array}$ \\
\hline
\end{tabular}
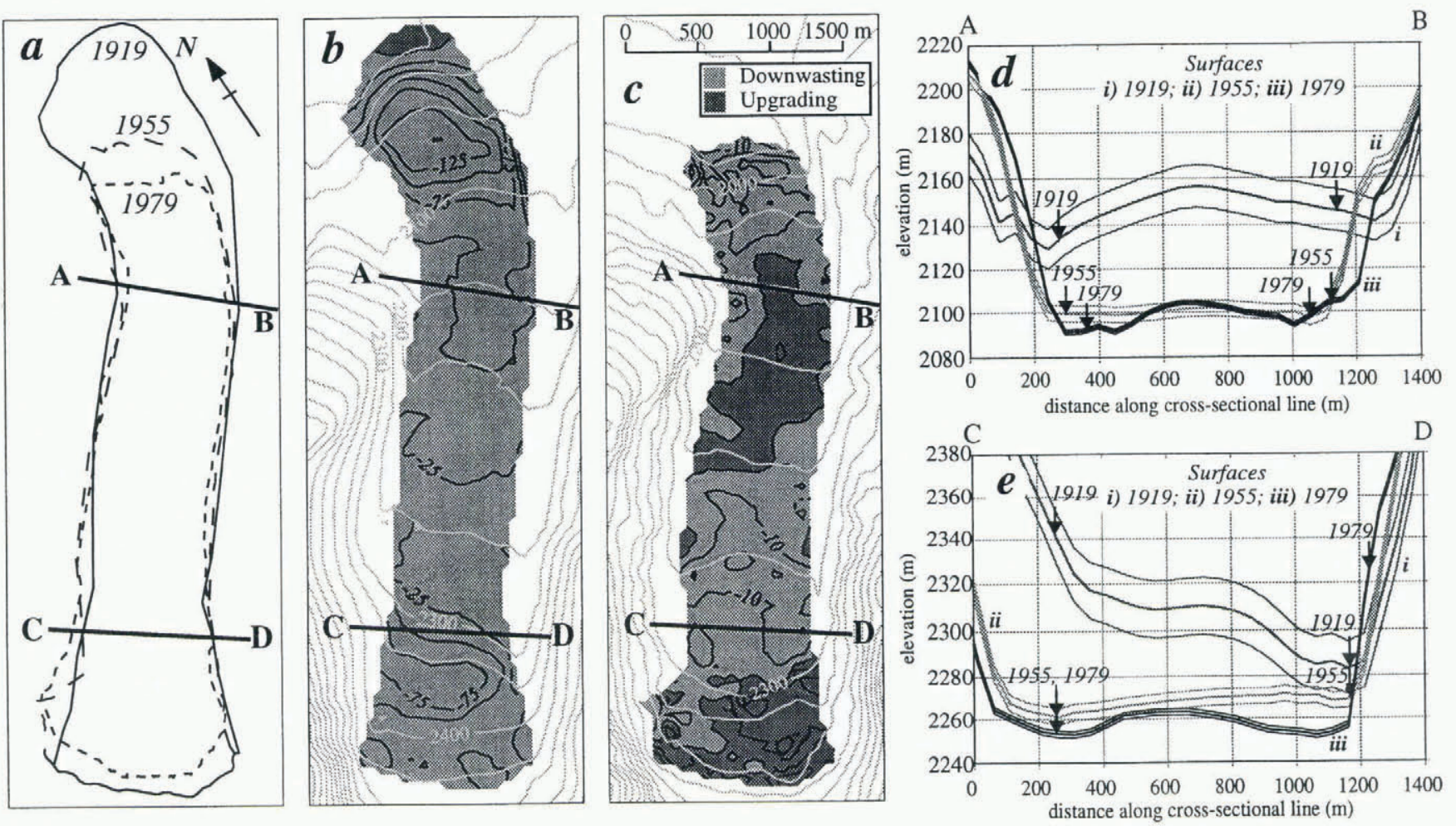

Fig. 2. Surface change of Athabasca Glacier. (a) Borders. Note non-coincident sections, especially on western margin. (b) Elevation change, 1919-55. Note apparent upgrading on terminus of glacier. (c) Elevation change, 1955-79. (d and e) Comparison of 1919, 1955 and 1979 cross-sections. Thick lines represent surface as digitized. Thin lines surrounding represent photogrammetric margin of error. Italicized years attached to arrows represent the edge of the glacier as interpreted for that map. Note non-coincidence of valley walls on the cross-sections. Since valley walls are steep, a small horizontal displacement results in a large vertical non-coincidence.

\section{Elevation change}

To calculate elevation change, nodes of identical $(x, y)$ location are compared between DEMs. Figures were prepared showing the distribution of elevation change over all of the nodes of a glacier surface. Figure $2 \mathrm{~b}$ and $\mathrm{c}$ show total elevation change of the glacier over the intervals 1919-55 and 1955-79 and indicate that elevation change is heterogenous over the glacier surface. The elevation change that the glacier displayed between 1919-55 (Fig. 2b) records an anomalous rise at the terminus, despite substantial volumetric loss in that interval. The rise as recorded is spurious, an artifact of the horizontal and vertical inaccuracies associated with the mapping, detailed below.

The amount of change registered at each of the nodes was recorded and averaged to find the mean elevation change of the surface over a given interval (Table 2).

\section{Volumetric change}

Total volumetric change between successive mappings is summarized in Table 2. The change between the successive maps is calculated within the borders of the earlier of the paired maps. Change has not been consistently negative. There have been periods of mass increase within an overall pattern of glacier shrinkage. The annual rate of volumetric loss between $1919-55$ is $-6.25 \times 10^{6} \mathrm{~m}^{3}$ year $^{-1}$, while the rate of volumetric change between $1955-79$ is less, being $-3.92 \times 10^{5} \mathrm{~m}^{3}$ year $^{-1}$. This is in agreement with the record of terminal recession discussed in Luckman (1988).

The results of volume and elevation change recorded in the intervals 1969-71 and 1971-73 show a great decline in volume and elevation between 1969-71 followed by a sharp gain between 1971-73. This is believed to be due to a systematic error in the production of the 1971 map, since it is 
Table 2. Total volumetric change of the complete ice surface, terminus $-2400 \mathrm{~m}, 1919-79$

\begin{tabular}{lrcr}
\hline Interval & $\begin{array}{c}\text { Total } \\
\text { volumetric change }\end{array}$ & $\begin{array}{c}\text { Photogrammetric uncertainty } \\
\text { of volumetric change }\left(\sigma_{\mathrm{v}}\right)\end{array}$ & $\begin{array}{c}\text { Mean total } \\
\text { elevation change }\end{array}$ \\
& $\mathrm{m}^{3} \times 10^{3}$ & $\mathrm{~m}^{3} \times 10^{3}$ & $\mathrm{~m}$ \\
\hline $1919-55$ & -225000 & 40070 & -54.70 \\
$1955-59$ & -5517 & 12475 & -0.90 \\
$1959-65$ & 3185 & 4208 & -0.90 \\
$1965-67$ & -315 & 5216 & -0.06 \\
$1967-69$ & 4863 & 5144 & 1.38 \\
$1969-71$ & -24160 & 5221 & -6.84 \\
$1971-73$ & 12940 & 5192 & 3.69 \\
$1973-75$ & -2163 & 5212 & -0.61 \\
$1975-77$ & 3719 & 5188 & -0.55 \\
$1977-79$ & -1953 & 5194 & \\
Total & & & \\
$1919-79:$ & -234000 & & \\
\hline
\end{tabular}

difficult to conceive of a process that could cause this sharp decline and rebound effect.

\section{MAGNITUDES OF UNCERTAINTY}

To quantify measures of uncertainty for both elevation and volumetric change, the precision of measurement of the source maps must be considered for the corresponding DEMs. Several different methods (listed in Table 1) were used to prepare the contour maps. Calculations of vertical uncertainty assume that the effects of horizontal uncertainty are small and that the uncertainty of vertical estimation at a point is primarily due to the distance from the point to the photographic station, given consistency in the optics of the cameras used. The effects of horizontal uncertainty are estimated with respect to georeferencing corrections.

\section{Vertical uncertainty}

Since distance to the photographic station is the primary factor in determining the precision of vertical estimation, a series of equations that describe the magnitude of uncertainty at given points on the glacier can be produced. Maps produced using aerial and terrestrial photogrammetry have different equations of uncertainty (Table 3).

The two varieties of terrestrial photogrammetry used have different precisions of angular measurement. Readings from the 1965-79 terrestrial photogrammetry (cf. Reid and Charbonneau, 1981) can be made to $l^{\prime}$ of arc (Young and others, 1978). The precision of angular measurement made from the 1919 photography was not stated in Cautley and others (1924), but was assumed to be $0.0846^{\circ}$ of arc from the focal length of the camera and the value estimated for the precision of measurement of the equipment used in the early 1920 s.

Of the measurements made using aerial photogrammetry, the 1959 map was studied by Paterson (1966), whose findings suggested that its precision was $2.0 \times 10^{-4}$ of flying height. No special verification was carried out for the 1955 map; thus, its precision of vertical estimation was taken to be the mean of the range of other empirical values produced for similar measurements as reported in Young and Arnold (1978): $4.5 \times 10^{-4}$ of flying height. Camera altitudes were markedly dissimilar: the 1955 photography was taken at a height of $10700 \mathrm{~m}$ a.s.l. and the 1959 photography was taken at $4110 \mathrm{~m}$ a.s.l.

These equations of uncertainty are applied to the entire area of the DEM representation of the glacier. Every raster grid node on the glacier surface was treated by the appropriate equations. This produced surfaces of uncertainty for each map. The surfaces of uncertainty produced were added to and subtracted from surfaces representing the elevation of the glacier for every year of measurement. Thus, the glacier for each year of mapping is represented by three surfaces. When different mappings are compared, values of elevation and volumetric change are calculated for each of the nine combinations of the six surfaces. The uncertainty of measurement, a measure of dispersal, is the standard deviation of the differences. Figure $2 \mathrm{~d}$ and e show the surface of the glacier for the cross-sections AB and CD (shown in Figure $2 \mathrm{a}-\mathrm{c}$ ) for the years 1919, 1955 and 1979. The surfaces of uncertainty associated with each year of mapping are displayed as thin lines surrounding the surface as digitized.

With quantities representing magnitudes of uncertainty, the imprecision of measurement can be compared to the values of elevation and volumetric change. This is shown in Table 2, which sums the values of uncertainty of measurement from the terminus to $2400 \mathrm{~m}$ for each of the intervals between successive mappings. In most intervals the uncer-

Table 3. Accuracy of vertical estimation for different maps or map series

\begin{tabular}{|c|c|c|c|c|c|}
\hline \multirow[t]{3}{*}{ Interval } & \multirow[t]{3}{*}{ Function } & \multirow[t]{3}{*}{ Photo type } & \multirow{3}{*}{$\begin{array}{c}\text { Flying height } \\
\text { m }\end{array}$} & \multicolumn{2}{|c|}{ Standard height error } \\
\hline & & & & $1950 \mathrm{~m}$ & $2400 \mathrm{~m}$ \\
\hline & & & & $\mathrm{m}$ & $\mathrm{m}$ \\
\hline 1919 & $Z_{\mathrm{n}}=D \tan \alpha$ & Terrestrial & - & $\approx 6.50$ & $\approx 14.00$ \\
\hline 1955 & $Z_{\mathrm{n}}=h \cdot 4.5 \times 10^{-4}$ & Aerial & 10700 & 3.94 & 3.74 \\
\hline 1959 & $Z_{\mathrm{n}}=h \cdot 2.0 \times 10^{-4}$ & Aerial & 4110 & 0.53 & 0.43 \\
\hline $1965-79$ & $Z_{\mathrm{n}}=D \tan \beta$ & Terrestrial & - & $\approx 0.50$ & $\approx 1.80$ \\
\hline
\end{tabular}

\footnotetext{
$Z_{\mathrm{n}}$ uncertainty of vertical estimation $(\mathrm{m})$.

$D$ distance from terrestrial photogrammetric station.

$h$ height above ground of aerial photogrammetry flight.

$\alpha$ precision of angular measurement of 1919 photogrammetry.

$\beta$ precision of angular measurement of terrestrial photogrammetry, 1965-79.
} 
Table 4. Relative magnitudes of error sources

\begin{tabular}{|c|c|c|}
\hline $\begin{array}{l}\text { Data source or data- } \\
\text { generating process }\end{array}$ & Type of error produced & Relative magnitude of error \\
\hline \multirow[t]{2}{*}{ Photograph } & Scale of photography & $\begin{array}{l}\text { Dealt with in greatest detail. Ranges from } \pm 0.43 \mathrm{~m} \text { for large-scale photography to } \pm \approx 14.0 \mathrm{~m} \\
\text { for small-scale terrestrial }\end{array}$ \\
\hline & $\begin{array}{l}\text { Closeness of ground control } \\
\text { points to measured objects }\end{array}$ & Not dealt with \\
\hline \multirow[t]{4}{*}{ Topographic map } & Scale & $\begin{array}{l}\text { Effects of scale on horizontal estimation were discussed. At the l } \sigma \text { level for the large-scale maps, } \\
\text { horizontal uncertainty was }<2 \mathrm{~m}\end{array}$ \\
\hline & Contour interval & A surface portrayed using a small contour interval would be better able to portray fine detail \\
\hline & Proficiency of operator & Not dealt with \\
\hline & $\begin{array}{l}\text { Tracing or interpolation of } \\
\text { contour lines }\end{array}$ & Not dealt with \\
\hline \multirow[t]{2}{*}{ Digitizing } & Proficiency of operator & Average displacement of digitized points from test lines: $19 \mu \mathrm{m}$ \\
\hline & Registration error & $\begin{array}{l}\text { Horizontal registration error measured using rms for various maps digitized. For the large-scale } \\
\text { maps this figure was } \approx 14 \mathrm{~m}\end{array}$ \\
\hline \multirow[t]{3}{*}{ Raster DEM } & Residuals & $\begin{array}{l}\text { A measure of how closely the surface matches the data points from which it was generated. } \\
\text { Residuals were small in flat areas }(\approx 8 \mathrm{~cm}) \text { and larger in steep areas }(\approx 30 \mathrm{~cm})\end{array}$ \\
\hline & Interpolation algorithm & Kriging generated surfaces that had a close match with the data points digitized \\
\hline & Grid spacing & Finer grid spacing produces more precise measures of area and volumetric change \\
\hline \multirow[t]{2}{*}{$\begin{array}{l}\text { Correction of geo- } \\
\text { referencing }\end{array}$} & $\begin{array}{l}\text { Limited number of points to } \\
\text { interpolate from }\end{array}$ & Not dealt with \\
\hline & $\begin{array}{l}\text { "Minimizing differences" } \\
\text { rather than rubber sheeting }\end{array}$ & Estimated the effects of a $10 \mathrm{~m}$ displacement \\
\hline $\begin{array}{l}\text { Area and volumetric } \\
\text { calculations }\end{array}$ & $\begin{array}{l}\text { Depends on fineness } \\
\text { of grid }\end{array}$ & Finer grid spacing produces more precise measures of area and volumetric change \\
\hline
\end{tabular}

tainty of volumetric change was greater than the calculated volumetric change. This is due to heterogeneity of change over the surface: part of the surface may be downwasting while another part upgrades. When change is measured over intervals finer than the entire studied surface, such as 10 or $50 \mathrm{~m}$ elevation zones, there is a much higher incidence of measured change being greater than the uncertainty of measurement.

\section{Horizontal uncertainty}

If maps do not overlay precisely, measures of change between them will be affected. These problems have been rectified, thus eliminating most of this imprecision.

Tests were performed to determine the magnitude of imprecision caused by a slight displacement in the horizontal plane such as that which could exist between different map series. Each of the digitized data points representing the 1955 surface had their georeferencing changed by $10 \mathrm{~m}$ horizontally in each of the eight cardinal and diagonal directions. Surfaces were generated again for each displacement, and volumetric change calculations for the 1955-59 interval were repeated.

The standard deviation of the eight recalculations and the undisplaced value was $2.8 \times 10^{6} \mathrm{~m}^{3}$. This is less than a quarter of the value of volumetric uncertainty associated with the limits of photogrammetric vertical estimation for that interval.

\section{Other sources of uncertainty}

The estimates of vertical and horizontal uncertainty discussed above account for only two of the potential sources of error. Table 4 lists other error sources involved in this method and, where they were quantified, reports the values produced.

\section{CONGLUSION}

The large-scale terrestrial photogrammetric maps were made at 2 year intervals. When the uncertainty of vertical estimation was calculated, it was apparent that large parts of the surface of the glacier often had a magnitude of elevation change that was less than the uncertainty of vertical estimation. When similar calculations were made for longer intervals, the amount of such areas declined as the time interval between maps increased. In a time of recession, this is a result to be expected: the uncertainty remains constant, but the magnitude of change increases. A greater interval between maps would allow a more effective measurement of change.

When a series of maps is created to measure change, the interval between them should be determined by a comparison of the expected magnitude of elevation change and the precision of measurement of mapping. Despite the problem of high imprecision in the 1919 and 1955 maps, their comparison (Table 2) reveals that very little of the change recorded between those two DEMs was less than the uncertainty of volumetric estimation. This is in contrast with many of the higher-precision DEMs which show substantial parts of the glacier having volumetric change that is less than the uncertainty of measurement.

This study demonstrates that since there are many sources of error in map-making and even more when maps are compared, extreme caution is needed when quantitative results are produced from the maps. In a study of this nature, it would be best to return to the original data sources and, using current software, produce DEMs directly from the photography which was used to make the maps.

\section{AGKNOWLEDGEMENTS}

The authors wish to acknowledge the financial support of Alberta Environment; the Atmospheric Environmental 
Service of Environment Canada; and U.S. Natural Sciences and Engineering Research Council Operating Grant No. OGP0038355.

\section{REFERENCES}

Cautley, R.W., J. N. Wallace and A. O. Wheeler. 1924. Report of the Commission appointed to delimit the boundary between the Provinces of Alberta and British Columbia. Part I. 1913-1916. Ottawa, Ont., Office of the Surveyor General. Interprovincial Boundary Commission.

Luckman, B. H. 1988. Dating the moraines and recession of Athabasca and Dome Glaciers, Alberta, Canada. Arct. Alp. Res., 20 (1), 40-54.

Parks Canada. 1980. The Columbia icefields; 1:50000. Special edition map. Ottawa, Parks Canada, Environment Canada.
Paterson, W. S. B. 1966. Test of contour accuracy on a photogrammetric map of Athabasca Glacier. Can. J. Earth Sci., 3 6), 909-915.

Reid, I. A. and J. O. G. Charbonneau. 1981. Glacier surveys in Alberta - 1979 Ottawa, Ont., Environment Canada. Inland Waters Directorate. Water Resources Branch. (IWD Report Series 69.)

Young, G. J. and K. C. Arnold. 1978. Orthophotomaps of glaciers: an evaluation of an automated method applied to Peyto Glacier, Alberta. Z Gletscherkd. Glazialgeol., 13(1-2), 1977, 99-110.

Young, G.J., J. E. Glynn, I. A. Reid and D. A. Sherstone. 1978. Mapping the Athabasca Glacier, Alberta, Canada, by orthophotography and by conventional methods. In International Symposium on New Technology for Mapping, Ottawa, Ontario, 26 October 1978. Proceedings. Ottawa, Ont., Canadian Institute of Surveying. International Society for Photogrammetry, 643 659. (Commission 4.) 